\title{
Intracellular Calcium Ion Concentration Measurement Using a Phase-modulation Fluorescence Lifetime Method with Compensation for Phase Shift due to the Presence of Proteins
}

\author{
Wataru InAmI, $* * * \dagger$ Nguen H. Viet, $* * *$ Atsuo MiYaKawa, $* * * * * *$ and Yoshimasa KaWata $* *, * * *$ \\ *Division of Global Research Leaders, Shizuoka University, Johoku, Naka, Hamamatsu, Shizuoka 432-8561, \\ Japan \\ **CREST, Japan Science and Technology Agency, Japan \\ *** Faculty of Engineering, Shizuoka University, Johoku, Naka, Hamamatsu, Shizuoka 432-8561, Japan
}

\begin{abstract}
The calcium ion concentration in cells was measured by a phase-modulation fluorescence lifetime method with compensation for proteins. A high-accuracy measurement of the calcium ion concentration is best realized by fluorescence lifetime measurements, because the fluorescence lifetime is independent of the fluorescence intensity. The fluorescence intensity is easily varied by the scattering of excitation and emission light in cells, photobleaching, the concentration of fluorochromes, and wavelength dispersion of optical elements. A phase-modulation fluorescence lifetime measurement, however, provides high accuracy and precision, and can measure not only the calcium ion concentration, but also other ion concentrations, such as that of magnesium, sodium, and potassium. We have examined the phase-modulation fluorescence lifetime shift using protein compensation in cells, and have measured the calcium ion concentration in cells stimulated with bradykinin.
\end{abstract}

(Received July 25, 2012; Accepted November 22, 2012; Published February 10, 2013)

\section{Introduction}

Intracellular free calcium ions control cellular functions as a second messenger. The measurement of intracellular free calcium ion concentrations $\left(\left[\mathrm{Ca}^{2+}\right] \mathrm{i}\right)$ is widely used to examine the functions of cell components, such as ion channels and the effects of cell exposure to reagents. ${ }^{1-4}\left[\mathrm{Ca}^{2+}\right]$ i is often measured with a calcium indicator, called Cameleon, ${ }^{5,6}$ which is a fusion protein of green fluorescent protein (GFP) and calmodulin, or a fluorescent calcium indicator of a low-weight molecule, such as fura- $2^{7,8}$ or calcium orange, ${ }^{9}$ fura-red,${ }^{10}$ etc.

In measurements using fluorescent calcium indicators of low molecular weight, the fluorescence intensity change of the calcium indicator determines $\left[\mathrm{Ca}^{2+}\right] \mathrm{i}$. However, the intensity is easily changed by the scattering of excitation and emission light, photobleaching, the concentration of fluorochromes, or wavelength dispersion of optical elements. In order to avoid these effects, ratiometric measurements ${ }^{7}$ are used to determine $\left[\mathrm{Ca}^{2+}\right] \mathrm{i}$ quantitatively. The measurements are based on the ratio between two fluorescence intensities at different wavelengths from a single dye. Ratiometric measurements are required for indicators that exhibit spectral shifts upon ion binding for quantitative ion measurements. Fura- $2^{7,8}$ and indo- $1^{11,12}$ can be used for this purpose, but cells are damaged by 340 to $380 \mathrm{~nm}$ ultraviolet light used for exciting the indicators, and the spectra of the indicators change due to interactions between the indicators and the protein in the cells. ${ }^{13}$ The Cameleon GFP

$\dagger$ To whom correspondence should be addressed.

E-mail: dwinami@ipc.shizuoka.ac.jp calcium sensor is also widely used for ratiometric measurements. Almost all ion indicators that are excited by visible light do not exhibit spectral shifts upon ion binding. These indicators are sensitive to any ion concentration change, but quantitative ion measurement cannot be realized. The absolute ion concentration cannot be determined by the fluorescence intensity, because it depends on the concentrations of fluorochromes, photobleaching, the intensity of the excitation light, and so on. Fluorescence lifetime measurements can realize quantitative ion measurements, although an indicator that does not exhibit spectral shifts upon ion binding must be used. Moreover, various low-molecular-weight indicators are readily available for $\mathrm{Ca}^{2+}, \mathrm{Na}^{+}, \mathrm{K}^{+}, \mathrm{Mg}^{2+}$, and $\mathrm{Cl}^{-}$measurements. The indicators of low molecular weight can be loaded to a cell in tens of minutes to $1 \mathrm{~h}$.

There are two types of fluorescence lifetime measurements: time-correlated single-photon counting (TCSPC) $)^{14}$ and a phase-modulation method. ${ }^{15,16}$ TCSPC method is a technique to record the decay curve of the fluorescence intensity. The decay curve is measured with pulsed excitation and time-gated detection, which is required for photon counting. The timing of the time-gated detection is varied relative to the excitation and the fluorescence intensities at different time delays after excitation. The phase-modulation method is based on measurements of the phase shift between the intensity modulated excitation and the emission signals. A high-speed detection system and intensity modulator of excitation light is utilized. A laser diode can also be used, and its intensity can be easily modulated with drive current modulation. ${ }^{17}$

A compact and low-cost system can be constructed for the phase-modulation method compared with TCSPC. The 


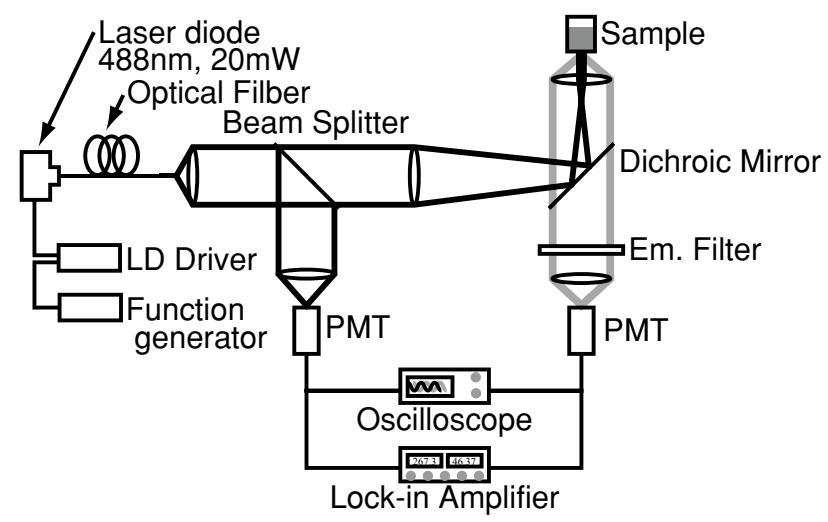

Fig. 1 Schematic diagram of the experimental optical set-up of the phase-modulation fluorescence lifetime method.

measurement time of the phase-modulation method is shorter than that of TCSPC, because photon pile-up limits the data acquisition rate of TCSPC, in which only one photon can be detected at a time. The intensity of excitation light in TCSPC must be adjusted to emit near single photons from fluorescence dye.

In this paper, we describe measurement of $\left[\mathrm{Ca}^{2+}\right] \mathrm{i}$ in cells with the phase-modulation method using the fluorescence lifetime change, ${ }^{18}$ while compensating for the interaction between proteins and the fluorescent dye. Specifically, we measured the fluorescence lifetime dependence on $\left[\mathrm{Ca}^{2+}\right] \mathrm{i}$ with serum albumin (BSA) for the compensation.

\section{Experimental}

Optical setup of the phase-modulation fluorescence lifetime method

Figure 1 shows a schematic diagram of the experimental optical setup of the phase-modulation fluorescence lifetime method. ${ }^{17}$ The light source was a blue laser diode (Nichia, NDS1113E) with $488 \mathrm{~nm}$ wavelength, and the maximum optical output power was $20 \mathrm{~mW}$. The laser diode was driven with a laser diode driver, ALP-7033CA (Asahi Data Systems), and the laser light output was modulated with a function generator (Agilent Technologies, N5181A).

The sinusoidally modulated excitation light was divided into two paths. The reflected light was detected with a photomultiplier tube (Hamamatsu Photonics, H6780-02) as a reference signal. The transmitted light was reflected with a dichroic mirror (Edmund Optics, NT47-421; cut-off wavelength, $497 \mathrm{~nm}$ ) and excited the fluorescence dye. The excited fluorescence light was collected by a lens, and then passed through a dichroic mirror, and then filtered by an emission filter (Semrock Inc., BLP01-488R-25; cut-on wavelength, $500 \mathrm{~nm}$ ) that would transmits only fluorescent light. The fluorescent light was detected by a photomultiplier tube. The fluorescent light had sinusoidal modulation, and the phase shift between the fluorescence and reference signal was measured with an oscilloscope (Agilent Technologies, DSO7104B) and a lock-in amplifier (Stanford Research Systems, SR844). The optical and electric components of the detection system of the reference and fluorescence light intensities were all the same so as to prevent any unnecessary phase shift in the electrical circuits.

The fluorescence lifetime can be determined by the phase shift. The lifetime is given by $\tau=1 / \omega \tan \phi=1 /(2 \pi \mathrm{f}) \tan \phi$,

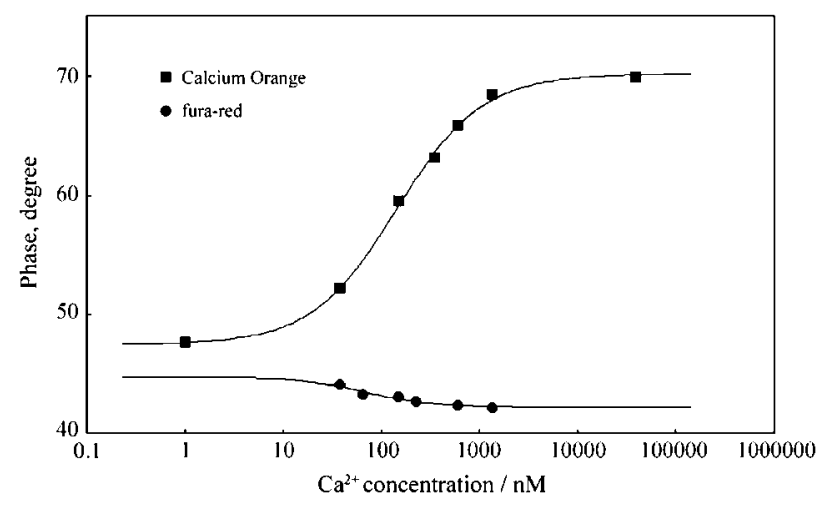

Fig. 2 Experimental result of the fluorescence lifetime as a function of the calcium ion concentration. The lifetimes of calcium orange and fura-red were measured with the phase-modulation fluorescence lifetime method at frequencies of 120 and $90 \mathrm{MHz}$, respectively.

where $\omega$ is the angular frequency, $f$ the frequency of the intensity modulation of excitation light, and $\phi$ the phase shift between the fluorescence and the reference signal.

\section{Production of reagent solutions}

We used the fluorescence calcium indicators, calcium orange (tetrapotassium salt, cell impermeant, C3013, Invitrogen), calcium orange AM (cell permeant, C3015, Invitrogen), and fura-red (tetrapotassium salt, cell impermeant, F14219, Invitrogen). Bovine serum albumin (BSA, lyophilized powder, $>96 \%$, heat-shocked fractionate, agarose gel electrophoresis (A9647, Sigma-Aldrich)) was used to examine the fluorescence lifetime change by the interaction between the protein and the fluorescence dye in a cell. The BSA is easily available, and is suited to simulate a cell with a high concentration of protein. Bradykinin acetate salt (B3259, Sigma-Aldrich), which increases $\left[\mathrm{Ca}^{2+}\right] \mathrm{i}$ in cells, was used for a stimulant.

We prepared a $\mathrm{Ca}^{2+}$ solution including $10 \mathrm{mM}$ HEPES, $20 \mathrm{mM} \mathrm{NaCl}, 130 \mathrm{mM} \mathrm{KCl}$, and $2 \mathrm{mM}$ EGTA. $\mathrm{CaCl}_{2}$ was varied from 0 to $2.0 \mathrm{mM}$ and $1 \mathrm{M} \mathrm{KOH}$ solution was added to increase making of the buffer's $\mathrm{pH}$ to 7.05. The recording medium for measuring $\left[\mathrm{Ca}^{2+}\right] \mathrm{i}$ in cells consisted of $20 \mathrm{mM}$ HEPES, $115 \mathrm{mM} \mathrm{NaCl}, 5.4 \mathrm{mM} \mathrm{KCl}, 0.8 \mathrm{mM} \mathrm{MgCl} 2,1.8 \mathrm{mM}$ $\mathrm{CaCl}_{2}$, and $13.8 \mathrm{mM}$ D-glucose adjusted to $\mathrm{pH} 7.4$ by adding $1 \mathrm{M} \mathrm{KOH}$.

Load of calcium orange in living cells and measurement of $\left[\mathrm{Ca}^{2+}\right] \mathrm{i}$ A nerve cell line of NG108-15 cells were cultured in a glassbased dish (3911-035, Asahi Glass) containing a culture medium. We exchanged the medium for $1 \mathrm{ml}$ of a recording medium including $10 \mu \mathrm{M}$ calcium orange $\mathrm{AM}$, and then the cells were incubated under conditions of $5 \% \mathrm{CO}_{2}$ and $37^{\circ} \mathrm{C}$ for $40 \mathrm{~min}$. We removed the recording medium, including calcium orange AM from the dish, and added the culture medium after washing it three times with $1 \mathrm{ml}$ of the recording medium. The cells were incubated for $1 \mathrm{~h}$. After incubation, the culture medium was exchanged for the recording medium again.

\section{Results of Calcium Ion Concentration Measurement}

\section{Fluorescence phase with calcium ions}

Figure 2 shows the experimental result of $\left[\mathrm{Ca}^{2+}\right] \mathrm{i}$ as a function of the phase delay of the fluorescence emission to the excitation light. We used a nonlinear least-squares method to fit the data 


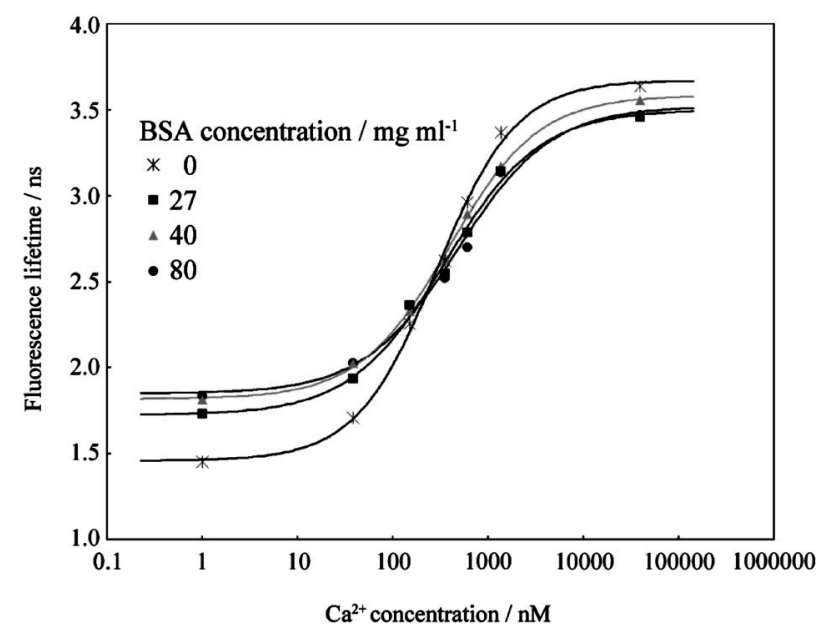

Fig. 3 Dependence of the fluorescence lifetime of calcium orange in a calcium ion solution including protein. The BSA protein concentrations were $0,26.7,40$, and $80 \mathrm{mg} / \mathrm{ml}$. The modulation frequency of the excitation light was $120 \mathrm{MHz}$.

to an inverse sigmoid curve and well-known dissociation constant $\left(K_{\mathrm{d}}\right)$ for calcium, indicators were used for the fitting. Calcium orange and fura-red were used as calcium ion indicators. The modulation frequencies of the excitation light intensity for the measurements with calcium orange and fura-red were 120 and $90 \mathrm{MHz}$, respectively. The $\left[\mathrm{Ca}^{2+}\right] \mathrm{i}$ was varied from 1 to $39000 \mathrm{nM}$, a concentration gradient that corresponds with that in a cell. The phase delay of the fluorescence emission of calcium orange increased from 47.3 to 70.1 degrees, and the phase delay of the fura-red decreased from 44.7 to 42.2 degrees. This indicated that the fluorescence lifetime of calcium orange increased and the fluorescence lifetime of fura-red decreased with an increase of the $\left[\mathrm{Ca}^{2+}\right]$ i. Previous reports ${ }^{4,19}$ show that the fluorescence lifetime of calcium orange bound calcium became longer and the fluorescence lifetime of fura-red bound calcium became shorter than that of only fura-red. There are calcium indicators that increase, and some that decrease the fluorescence lifetime, when the calcium indicators are bound to calcium ions. ${ }^{19}$ The fluorescence lifetime change is caused by photo-induced electron transfer, ${ }^{20}$ but it is difficult to estimate the fluorescence lifetime of indicators bound to calcium. Binding calcium and a calcium indicator change the electronic structure of the calcium indicator. In the case of calcium orange, the calcium ion prevents electron transfer, and it makes the fluorescence lifetime longer. In the case of fura-red, molecules in an excited state receive an electron, which quenches the fluorescence. As a result, the lifetime becomes shorter. The electronic structure of a fluorescence molecule determines whether the fluorescence quenches. The variation of the phase shift of calcium orange was larger than that of fura-red. Thus, the sensitivity of calcium orange was higher than that of furared. Calcium orange is therefore suitable for $\left[\mathrm{Ca}^{2+}\right] \mathrm{i}$ measurements in cells.

Change of fluorescence lifetime by coexistence of proteins and calcium ions

In order to quantitatively improve the $\left[\mathrm{Ca}^{2+}\right] \mathrm{i}$ measurement, we investigated the fluorescence lifetime of a calcium indicator in a calcium ion solution that included proteins. Low-molecularweight calcium indicators interact easily with proteins, which
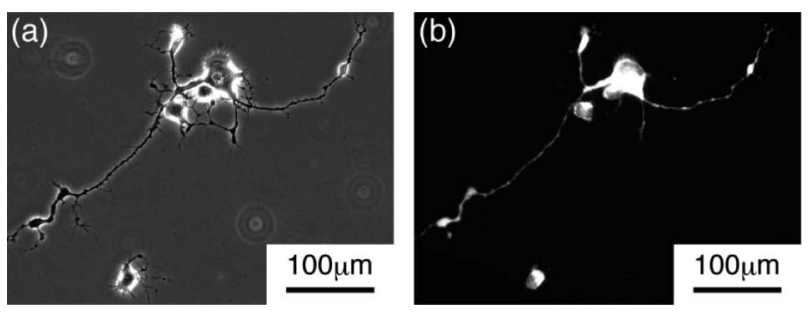

Fig. 4 Images of nerve cell line NG108-15 cell dyed with calcium orange: (a) phase contrast, (b) fluorescence.

changes the fluorescence lifetime. ${ }^{21}$ Because there are proteins in cells, it is difficult to quantify intracellular $\left[\mathrm{Ca}^{2+}\right] \mathrm{i}$. We thus compensated for the fluorescence lifetime change caused by the interaction between the indicator and the proteins.

Figure 3 shows the dependence of the fluorescence lifetime of calcium orange in a calcium ion solution that included the protein BSA, which is easily available. The BSA protein concentrations were $0,26.7,40$, and $80 \mathrm{mg} / \mathrm{ml}$. The fluorescence lifetime of the indicator in the calcium ion solution including BSA was changed compared with that in calcium ion solution without BSA. In the case of $80 \mathrm{mg} / \mathrm{ml} \mathrm{BSA}$, the fluorescence lifetime lengthened from 1.47 to $1.86 \mathrm{~ns}$ with $1 \mathrm{nM} \mathrm{Ca}^{2+}$, but it shortened from 3.66 to $3.49 \mathrm{~ns}$ with $39000 \mathrm{nM} \mathrm{Ca}^{2+}$. Similarly, in the case of $40 \mathrm{mg} / \mathrm{ml} \mathrm{BSA}$, the fluorescence lifetimes were 1.83 and $3.56 \mathrm{~ns}$ with $1 \mathrm{nM}$ and $39000 \mathrm{nM} \mathrm{Ca}^{2+}$, respectively. We found that the fluorescence lifetimes did not change upon varying the BSA concentration range from 40 to $80 \mathrm{mg} / \mathrm{ml}$. When the BSA concentration was $40 \mathrm{mg} / \mathrm{ml}$ or more, the BSA was titrated against the calcium orange, and the reactions reached equilibrium. The fluorescence lifetime hence did not depend on the BSA concentration for BSA concentrations of 40 and $80 \mathrm{mg} / \mathrm{ml}$. The result is similar to an experimental result performed using fura- $2 .{ }^{13}$ This BSA concentration range is the same as that of the total protein in living cells. ${ }^{21}$ Therefore, while it is necessary to compensate for the presence of proteins within cells, the concentration does not matter if it is within a physiological range.

\section{Measurement of $\left[\mathrm{Ca}^{2+}\right] \mathrm{i}$ in living cells}

Figure 4 shows observation results for the nerve cell line NG108-15. Calcium orange AM was loaded into cells to measure $\left[\mathrm{Ca}^{2+}\right]$ i. Figures $4(\mathrm{a})$ and $4(\mathrm{~b})$ were obtained with phase contrast and fluorescence microscopy, respectively. It is clear that calcium orange was loaded into the entire cell, as shown in Fig. 4(b).

Figure 5 shows the experimental result of a temporal $\left[\mathrm{Ca}^{2+}\right] \mathrm{i}$ change in living NG108-15 cells. The solid line (a) shows $\left[\mathrm{Ca}^{2+}\right] \mathrm{i}$ calculated from the compensated calibration curve, and solid line (b) shows [ $\left.\mathrm{Ca}^{2+}\right]$ i calculated from the non-compensated calibration curve. We measured the $\left[\mathrm{Ca}^{2+}\right] \mathrm{i}$ of two cells because an individual difference of the $\left[\mathrm{Ca}^{2+}\right] \mathrm{i}$ is large. Cells were stimulated with $1 \mu \mathrm{M}$ bradykinin, which induces a $\left[\mathrm{Ca}^{2+}\right] \mathrm{i}$ increase. The recording medium in the glass-based dish was perfused with peptide after starting of the measurement. The $\left[\mathrm{Ca}^{2+}\right] \mathrm{i}$ was calculated from the calibration curve with and without compensation from the change of the phase delay of the fluorescence emission with the protein present. The fluorescence lifetime was longer immediately after stimulation. The peak $\left[\mathrm{Ca}^{2+}\right] \mathrm{i}$ was about $90-200 \mathrm{nM}$, which then decreased quickly. The $\left[\mathrm{Ca}^{2+}\right]$ i without compensation was $1.5-2.5$-times higher than that with compensation at the maximum, because the 


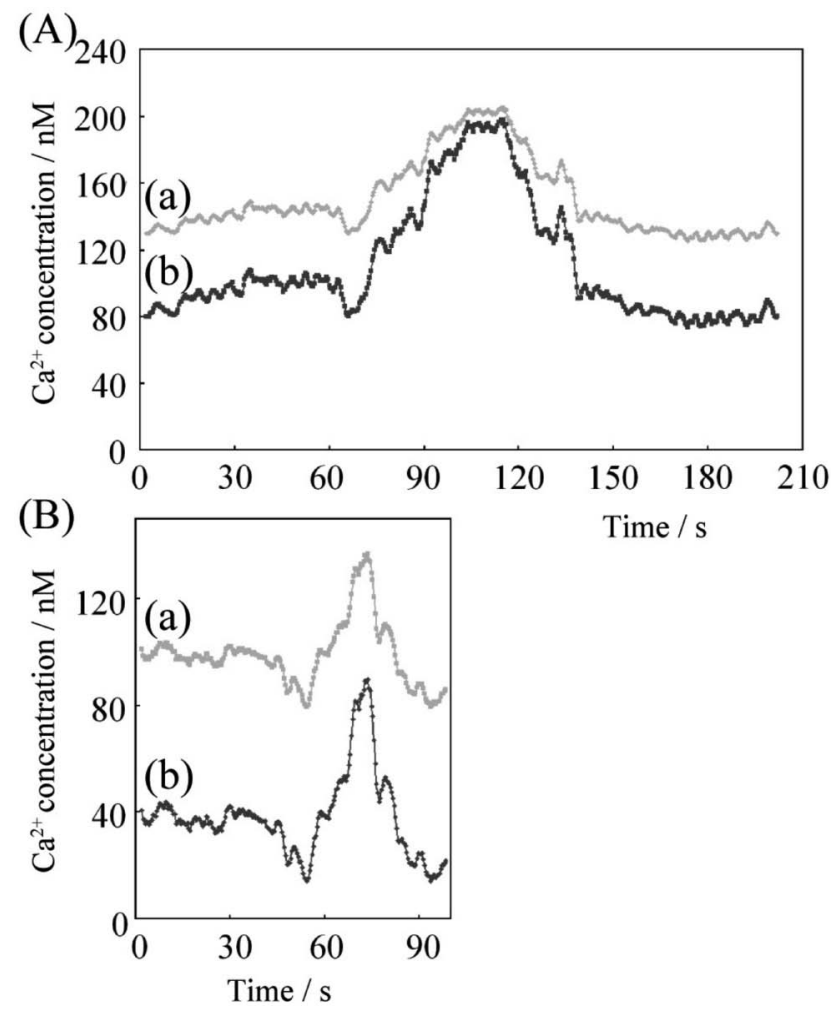

Fig. 5 Intracellular calcium ion concentration change of the NG108-15 cells with $1 \mu \mathrm{M}$ bradykinin stimulation. The solid line (a) shows $\left[\mathrm{Ca}^{2+}\right] \mathrm{i}$ calculated from the compensated calibration curve and the solid line (b) shows $\left[\mathrm{Ca}^{2+}\right] \mathrm{i}$ calculated from the non-compensated calibration curve. We showed two experimental results ((A) and (B)) of the $\left[\mathrm{Ca}^{2+}\right] \mathrm{i}$ measurements, because an individual difference of the specimens.

fluorescence lifetime with the protein become longer in Fig. 3 . For $\left[\mathrm{Ca}^{2+}\right] \mathrm{i}$ of $200 \mathrm{nM}$, the compensated value and uncompensated value were almost equal, because the difference between the compensated and uncompensated fluorescence lifetime decreased in the range of $\left[\mathrm{Ca}^{2+}\right]$ i from 100 to $1000 \mathrm{nM}$ (Fig. 3). The difference between the compensated and uncompensated fluorescence lifetime became large when $\left[\mathrm{Ca}^{2+}\right]$ i was below $100 \mathrm{nM}$ and more than $1000 \mathrm{nM}$. The results agree with a previous report. ${ }^{13}$

\section{Conclusions}

Advantage of $\left[\mathrm{Ca}^{2+}\right] \mathrm{i}$ measurement with the phase-modulation fluorescence lifetime method

We measured $\left[\mathrm{Ca}^{2+}\right] \mathrm{i}$ with the phase-modulation method, and realized accurate $\left[\mathrm{Ca}^{2+}\right] \mathrm{i}$ measurements by compensation of the phase change with the presence of protein. The measured $\left[\mathrm{Ca}^{2+}\right] \mathrm{i}$ with protein was $1.5-2.5$-times higher than that without protein at the maximum. The fluorescence emission phase delay was constant in a protein concentration range of 40 to $80 \mathrm{mg} / \mathrm{ml}$, which corresponds with that in normal cells. We also successfully measured $\left[\mathrm{Ca}^{2+}\right] \mathrm{i}$ in living NG108-15 cells with bradykinin stimulation. $\left[\mathrm{Ca}^{2+}\right] \mathrm{i}$ increased rapidly to $200 \mathrm{nM}$ with stimulation and then decreased to the same concentration as that before stimulation. The method can potentially measure not only a $\left[\mathrm{Ca}^{2+}\right] \mathrm{i}$, but also the concentrations of other ions, such as $\mathrm{Na}^{+}, \mathrm{K}^{+}, \mathrm{Mg}^{2+}$, and $\mathrm{Cl}^{-}$. It is also possible to measure multiple ions simultaneously in cells.

\section{Future developments}

We constructed the calibration curve in the environment, which is so as approximately equal to the intracellular environment, to improve the accuracy of the $\left[\mathrm{Ca}^{2+}\right] \mathrm{i}$ measurement. In the experiment, we used the BSA to compensate for the fluorescence lifetime change caused by the interaction between the indicator and proteins, but there are various proteins in a cell.

We are developing a two-dimensional scan system using a galvanometer mirror to measure the ion concentration distribution in cells. Since the fluorescence lifetime of an indicator is below $10 \mathrm{~ns}$, it seems that by using the phasemodulation method, the measuring time at one point can be shortened below $1 \mu \mathrm{s}$. Hence, it will only take $65.536 \mathrm{~ms}$ to take a $256 \times 256$ pixel image. The phase-modulation method will also be applicable to fluorescence correlation spectroscopy. More information from cells can be obtained for studies of various cellular activities. The phase-modulation method provides quantitative measurements of multiple ion concentrations in cells, and helps to reveal cell functions.

\section{References}

1. R. Y. Tsien, Methods Cell Biol., 1989, 30, 127.

2. D. A. Williams, K. E. Fogarty, R. Y. Tsien, and F. S. Fay, Nature, 1985, 318, 558.

3. J. C. Sáez, J. A. Connor, D. C. Spray, and M. V. Bennett, PNAS, 1989, 86, 2708.

4. A. Takahashi, P. Camacho, J. D. Lechleiter, and B. Herman, Physiol. Rev., 1999, 79, 1089.

5. A. Miyawaki, J. Llopis, R. Heim, J. M. McCaffery, J. A. Adams, M. Ikura, and R. Y. Tsien, Nature, 1997, 388, 882.

6. K. Horikawa, Y. Yamada, T. Matsuda, K. Kobayashi, M. Hashimoto, T. Matsu-ura, A. Miyawaki, T. Michikawa, K. Mikoshiba, and T. Nagai, Nature Methods, 2010, 7, 729.

7. P. L. Becker and F. S. Fay, Am. J. Physiol. Cell Physiol., 1987, 253, C613.

8. E. F. Etter, A. Minta, M. Poenie, and F. S. Fay, Proc. Natl. Acad. Sci., 1996, 93, 5368.

9. M. Eberhard and P. Erne, Biochem. Biophys. Res. Commun., 1991, 180, 209.

10. S. Reader, M. Marion, and F. Denizeau, Toxicology, 1993, 80, 117.

11. G. Grynkiewicz, M. Poenie, and R. Y. Tsien, J. Biol. Chem., 1985, 260, 3440 .

12. C. H. June and P. S. Rabinovitch, Method. Cell Biol., 1990, 32,37 .

13. A. Miyakawa, T. Makino, A. Tamagawa, and K. Ozaki, Bunseki Kagaku, 1989, 38, 643.

14. D. V. O'Connor and D. Phillips, "Time-Correlated Single Photon Counting", 1984, Academic Press, London.

15. E. A. Bailey and G. K. Rollefson, J. Chem. Phys., 1953, 21, 1315.

16. R. D. Spencer and G. Weber, Ann. NY Acad. Sci., 1969, $158,361$.

17. P. Harms, J. Sipior, N. Ram, G. M. Carter, and G. Rao, Rev. Sci. Instrum., 1999, 70, 1535.

18. J. R. Lakowicz, H. Szmacinski, K. Nowaczyk, W. J. Lederer, M.S. Kirby, and M. L. Johnson, Cell Calcium, 1994, 15, 7.

19. J. R. Lakowicz, "Principles of Fluorescence Spectroscopy", 3rd ed., 2006, Springer, New York.

20. K. Yoshiki, H. Azuma, K. Yoshioka, and M. Hashimoto, 
Opt. Rev., 2005, 12, 415.

21. M. Konishi, A. Olson, S. Hollingworth, and S. M. Baylor, 